\title{
Real-world experience at a Scottish university teaching hospital regarding the tolerability and persistence with topical Ciclosporin $0.1 \%$ (Ikervis) treatment in patients with dry eye disease
}

\author{
Jennifer Hind ${ }^{1}$ Elisabeth Macdonald ${ }^{1}$. David Lockington $\mathbb{B}^{1}$ \\ Received: 2 October 2018 / Accepted: 12 November 2018 / Published online: 29 November 2018 \\ (c) The Royal College of Ophthalmologists 2018
}

\section{Introduction}

The recent DEWS II report has recognised the inflammatory component of dry eye disease (DED), and highlighted the use of topical ciclosporin as a management option [1]. Ciclosporin A $(1 \mathrm{mg} / \mathrm{ml})$ in a cationic emulsion (Ikervis, Santen) was approved for once daily use by the Scottish Medical Consortium for the treatment of severe keratitis in adult patients with DED that has not improved despite treatment with tear substitutes in October 2015. The key published studies (SANSIKA [2] and SICCANOVE [3]) both reported issues with drop instillation pain (29.2-54.5\%) and subsequent discontinuation of treatment $(9.9-10.4 \%)[2,3]$. We wished to evaluate our initial real-world experiences with Ikervis in terms of patient tolerability and persistence of therapy.

\section{Methods}

All patients prescribed topical Ikervis by two consultant ophthalmologists from October 2015 to May 2018 were identified from the NHS Greater Glasgow and Clyde pharmacy database. Their electronic patient record was reviewed to identify patient demographics, indication, concurrent topical medication, adverse events and whether Ikervis was tolerated or discontinued.

David Lockington

davidlockington@hotmail.com

1 Tennent Institute of Ophthalmology, Gartnavel General Hospital, 1053 Great Western Road, Glasgow G12 0YN, UK

\section{Results}

A total of 52 patients were identified (13 male, 39 female). The mean age was 58 years (range 19-91). The underlying aetiology for keratitis and DED in this patient group is outlined in Table 1. Mean duration of treatment with Ikervis was 11 months (median 8.5; range 2-30). Sixty three percent of patients (33/52) were also treated with a tapering dose of topical steroids for the first month during the initiation phase of Ikervis use. All patients remained on long-term topical lubrication treatment at least 4 times per day. At last casenote review in September 2018, Ikervis was well tolerated and treatment persisted successfully in $88 \%$ (46/52) of patients. Only 6 patients discontinued Ikervis due to intolerance in the time period identified, although 2 were able to restart and persist (intolerant of treatment $4 / 52 ; 7.7 \%$ ). The reason stated for lack of persistence was local irritation, burning, or stinging in all 6 cases $(11.5 \%)$. These symptoms were manifested despite initial concurrent treatment with 1 month of topical steroids in 5 out of the 6 patients.

Table 1 Table detailing underlying aetiology for keratitis and dry eye disease in this patient group prior to starting Ikervis treatment

\begin{tabular}{ll}
\hline Other associated conditions contributing to dry eye symptoms & $N(\%)$ \\
\hline Sjogrens/Rheumatoid Arthritis & $21(40.4)$ \\
Blepharitis/lid margin disease & $11(21.6)$ \\
Allergy/atopic eye disease & $6(11.5)$ \\
Exposure/neurotrophic cornea/thyroid eye disease & $3(5.8)$ \\
Salzmann nodules & $2(3.8)$ \\
Pterygium & $2(3.8)$ \\
Previous penetrating keratoplasty & $1(1.9)$ \\
Vitamin A deficiency & $1(1.9)$ \\
Chemotherapy-related dry eye & $1(1.9)$ \\
Thygeson's keratitis & $1(1.9)$ \\
Other (zoster, ectodermal dysplasia, unknown) & $3(5.8)$ \\
\hline
\end{tabular}




\section{Conclusion}

Ikervis has been marketed as a dry eye product with less tolerance issues than other forms of topical ciclosporin (predominantly due to vehicle differences) and effective as a once daily dose (reducing instillation frequency and associated discomfort) [4]. In our study, Ikervis was tolerated in the majority of these DED patients with reasonable treatment duration (mean 11 months). However, local ocular irritation led to intolerance of treatment in a small number of patients (7.7\%). It has been suggested that concurrent use of topical steroids during the initiation of topical ciclosporin use can improve tolerance by reducing local ocular side effects [5]. This appeared to be the experience for most of our patients, but was not universal, reflecting the severity and complexity of DED. The SANSIKA and SICCANOVE studies suggested that initial ocular irritation decreased with longterm Ikervis use [2, $3,6,7]$. Our small study provides real-world experience data regarding the use, persistence and tolerability of topical Ikervis outside the controlled confines of these key clinical trials.

\section{Compliance with ethical standards}

Conflict of interest The authors declare that they have no conflict of interest.

\section{References}

1. Jones L, Downie LE, Korb D, Benitez-Del-Castillo JM, Dana R, Deng SX, et al. TFOS DEWS II management and therapy report. Ocul Surf. 2017;15:575-628.

2. Leonardi A, Van Setten G, Amrane M, Ismail D, Garrigue JS, Figueiredo FC, et al. Efficacy and safety of $0.1 \%$ cyclosporine A cationic emulsion in the treatment of severe dry eye disease: a multicenter randomized trial. Eur $\mathrm{J}$ Ophthalmol. 2016;26:287-96.

3. Baudouin C, Figueiredo FC, Messmer EM, Ismail D, Amrane M, Garrigue JS, et al. A randomized study of the efficacy and safety of $0.1 \%$ cyclosporine A cationic emulsion in treatment of moderate to severe dry eye. Eur J Ophthalmol. 2017;27:520-30.

4. Lallemand F, Daull P, Benita S, Buggage R, Garrigue JS. Successfully improving ocular drug delivery using the cationic nanoemulsion, novasorb. J Drug Deliv. 2012;604204:27.

5. Sheppard JD, Donnenfeld ED, Holland EJ, Slonim CB, Solomon R, Solomon KD, et al. Effect of loteprednol etabonate $0.5 \%$ on initiation of dry eye treatment with topical cyclosporine $0.05 \%$. Eye Contact Lens. 2014;40:289-96.

6. Leonardi A, Messmer EM, Labetoulle M, Amrane M, Garrigue JS, Ismail D, et al. Efficacy and safety of $0.1 \%$ ciclosporin A cationic emulsion in dry eye disease: a pooled analysis of twodoublemasked, randomised, vehicle-controlled phase III clinical studies. Br JOphthalmol. 2018 Mar 15. pii: bjophthalmol-2017-311801. https://doi.org/10.1136/bjophthalmol-2017-311801.

7. Baudouin C, de la Maza MS, Amrane M, Garrigue JS, Ismail $\mathrm{D}$, Figueiredo FC, et al. One-year efficacy and safety of $0.1 \%$ cyclosporine a cationic emulsion in the treatment of severe dry eye disease. Eur J Ophthalmol. 2017;27:678-85.

\title{
Unique presentation of congenital cataract concurrent with microcornea, microphthalmia plus posterior capsule defect in monozygotic twins caused by a novel GJA8 mutation
}

\author{
Hongfang Zhang ${ }^{1} \cdot$ Zhenji Chen $^{1} \cdot$ Kaiwen $\mathrm{He}^{1} \cdot$ Pingjun Chang ${ }^{1} \cdot$ Yinying Zhao ${ }^{1} \cdot$ Xiufeng Huang $^{1} \cdot{\mathrm{Jin} \mathrm{Li}^{1}}^{1}$ \\ Zibing Jin $\left(^{1}\right)^{1}$ Yun-e Zhao ${ }^{1}$
}

Received: 22 December 2017 / Revised: 15 July 2018 / Accepted: 5 October 2018 / Published online: 29 November 2018

(c) The Author(s) 2018. This article is published with open access

\footnotetext{
These authors contributed equally: Hongfang Zhang and Zhenji Chen

Zibing Jin

jinzb@mail.eye.ac.cn

$\triangle$ Yun-e Zhao

zyehzeye@126.com

1 The Eye Hospital of Wenzhou Medical University, School of Ophthalmology and Optometry, The State Key Laboratory of Ophthalmology, Optometry and Vision Science, 325027

Wenzhou, China
}

Congenital cataracts are the most common diseases which account for 10-30\% of blindness in children [1]. Multiple genetic mutations contribute to the progression of this genetically heterogeneous and complex disease. Among the reported causative congenital cataract mutations, approximately one quarter are connexin genes, including Connexin 46 which is encoded by GJA3 and Connexin 50 which is encoded by GJA8 [2].

In this study, we encountered four generations of a Chinese family with bilateral congenital cataracts at the Eye Hospital of Wenzhou Medical University. Among the four affected 